\title{
Elucidation of the Impact of P-glycoprotein and Breast Cancer Resistance Protein on the Brain Distribution of Catechol-O-Methyltransferase Inhibitors ${ }^{\circledR}$
}

\author{
Joana Bicker, Ana Fortuna, Gilberto Alves, Patrício Soares-da-Silva, and Amílcar Falcão
}

Laboratory of Pharmacology, Faculty of Pharmacy (J.B., A.Fo., A.Fa.), and Center for Neuroscience and Cell Biology (J.B., A.Fo., G.A., A.Fa.), University of Coimbra, Coimbra, Portugal; Health Sciences Research Centre, University of Beira Interior, Covilhã, Portugal (G.A.); Department of Research and Development, BIAL, Sao Mamede do Coronado, Portugal (P.S.-d.S.); and Department of Pharmacology and Therapeutics, Faculty of Medicine, University of Porto, Porto, Portugal (P.S.-d.S.)

Received August 7, 2017; accepted September 13, 2017

\begin{abstract}
P-glycoprotein (P-gp) and breast cancer resistance protein (BCRP) are clinically important efflux transporters that act cooperatively at the blood-brain barrier, limiting the entry of several drugs into the central nervous system (CNS) and affecting their pharmacokinetics, therapeutic efficacy, and safety. In the present study, the interactions of catechol-Omethyltransferase (COMT) inhibitors (BIA 9-1059, BIA 9-1079, entacapone, nebicapone, opicapone, and tolcapone) with P-gp and BCRP were investigated to determine the contribution of these transporters in their access to the brain. In vitro cellular accumulation and bidirectional transport assays were conducted in Madin-Darby canine kidney (MDCK) II, MDCK-MDR1, and MDCK-BCRP cells. In vivo pharmacokinetic studies were carried out for tolcapone and BIA 9-1079 in rats, with and without elacridar, a well-known P-gp and BCRP modulator. The
\end{abstract}

\section{Introduction}

During preclinical drug development stages, it is essential to characterize the brain pharmacokinetics of new drug candidates and determine the rate and extent at which compounds are capable of crossing the blood-brain barrier (BBB) and reaching the central nervous system (CNS). This evaluation is relevant for CNS-active and peripherally active drugs since, potentially, adverse side effects can arise from an undesired brain exposure (Bungay et al., 2015). Hence, greater knowledge of general drug distribution to the brain will contribute to the adoption of drug design strategies that increase or restrict access through the BBB, thereby minimizing the risk of late-stage failures and enhancing preclinical and clinical success. This may be achieved by combining the optimization of the intrinsic permeability of a compound

This work was funded by the European Regional Development Fund (FEDER) through the Operational Programme Competitiveness Factors, COMPETE; and national funds by the Foundation for Science and Technology [Project SFRH/BD/78256/2011]; and was also supported by BIAL-Portela \& Ca S.A.

https://doi.org/10.1124/dmd.117.077883.

S This article has supplemental material available at dmd.aspetjournals.org. results suggest that BIA 9-1079, nebicapone, and tolcapone inhibit BCRP in a concentration-dependent manner. Moreover, with net flux ratios higher than 2 and decreased over $50 \%$ in the presence of verapamil or Ko143, BIA 9-1079 was identified as a P-gp substrate while BIA 9-1059, entacapone, opicapone, and nebicapone were revealed to be BCRP substrates. In vivo, brain exposure was limited for tolcapone and BIA 9-1079, although tolcapone crossed the bloodbrain barrier at a greater rate and to a greater extent than BIA 9-1079. The extent of brain distribution of both compounds was significantly increased in the presence of elacridar, attesting to the involvement of efflux transporters. These findings provide relevant information and improve the understanding of the mechanisms that govern the access of these COMT inhibitors to the CNS.

ABBREVIATIONS: AP, apical; AUC, area under the curve; $\mathrm{AUC}_{0-\mathrm{t}}$, area under the concentration-time curve from time zero to the last measurable concentration; BBB, blood-brain barrier; BCRP, breast cancer resistance protein; BL, basolateral; CNS, central nervous system; COMT, catechol$O$-methyltransferase; DMSO, dimethylsulfoxide; $\mathrm{ER}$, efflux ratio; $f_{\mathrm{u}, \text { brain }}$, unbound drug fraction in the brain; $f_{\mathrm{u}}$, brain,corrected; corrected unbound drug

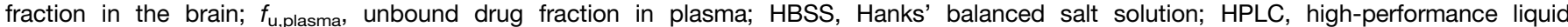
chromatography; MDCK, Madin-Darby canine kidney; MTT, 3-(4,5-dimethylthiazol-2-yl)-2,5-diphenyltetrazolium bromide; Na-F, sodium fluorescein; $P_{\text {app }}$, apparent permeability coefficient; P-gp, P-glycoprotein; TEER, transepithelial electrical resistance. 
transporters involved in drug disposition at the brain endothelium, including P-gp and BCRP (Giacomini et al., 2010; European Medicines Agency, 2012; Food and Drug Administration, 2012).

The aim of the present work was to identify P-gp and BCRP substrates and/or inhibitors among catechol- $O$-methyltransferase (COMT) inhibitors and estimate the influence of these transporters on their CNS penetration. COMT inhibitors are used in combined therapy for the treatment of Parkinson's disease to improve the bioavailability and efficacy of L-DOPA (Gonçalves et al., 2012; Kiss and Soares-da-Silva, 2014; Silva et al., 2016). Currently, there are three COMT inhibitors available in the market: entacapone; tolcapone, only used in patients unresponsive to other treatments and with monitoring of liver function; and opicapone, since its recent approval by the European Medicines Agency in June 2016 (Kiss and Soares-da-Silva, 2014; Annus and Vécsei, 2017). The peripheral (BIA 9-1059, BIA 9-1079, entacapone, and opicapone) and/or central (nebicapone and tolcapone) enzymatic inhibition displayed by these compounds justify the investigation of the role that P-gp and/or BCRP may have in their access to the CNS (Learmonth et al., 2002; Napolitano et al., 2003; Parada and Soares-da-Silva, 2003; Kiss et al., 2008; Bonifácio et al., 2014).

Despite intensive research concerning in vitro BBB models, immortalized brain endothelial cell lines often exhibit paracellular leakiness caused by a defective formation of tight junctions, which renders them unsuitable for BBB permeability screens (Abbott et al., 2014; Bicker et al., 2014). Therefore, surrogate models are frequently applied to identify compounds that may interact with P-gp and BCRP at the BBB (Mahar Doan et al., 2002; Wang et al., 2005; Feng et al., 2008; Hakkarainen et al., 2010; Hellinger et al., 2012; Chen et al., 2013; Hu et al., 2014), inclusively as screening tools in the pharmaceutical industry (Reichel, 2014). Consequently, in vitro cell-based assays were herein performed with Madin-Darby canine kidney (MDCK) type II cells as a surrogate BBB model, including stably transfected lines with MDR1 (MDCK-MDR1) or ABCG2 genes (MDCK-BCRP) of human origin. Intracellular accumulation assays were carried out to demonstrate transporter functionality and identify potential P-gp and BCRP inhibitors, while P-gp and BCRP substrates were identified by resorting to validated bidirectional transport assays.

Finally, in vivo studies were performed for BIA 9-1079, an active major metabolite of opicapone in rat, and for tolcapone, to determine and compare their extent of equilibration between plasma and brain and intrabrain distribution. Elacridar, a third-generation potent P-gp and
BCRP modulator, was also coadministered to assess the impact of efflux inhibition on the brain distribution of these compounds.

\section{Materials and Methods}

Chemicals and Reagents. Reference compounds used in cell-based assays (carbamazepine, propranolol, trazodone, cimetidine, quinidine, and sulfasalazine) were obtained from Sigma-Aldrich (St. Louis, MO) with the exception of atenolol (Acros Organics brand), which was acquired from ThermoFisher Scientific (Waltham, MA). Test compounds included BIA 9-1059, BIA 9-1079, entacapone, nebicapone, opicapone, and tolcapone and were kindly supplied by BIAL-Portela \& Ca., S.A. (Sao Mamede do Coronado, Portugal). Their chemical structure is represented in Fig. 1. Acetonitrile [high-performance liquid chromatography (HPLC) gradient grade], methanol (HPLC gradient grade), and dimethylsulfoxide (DMSO) were acquired from Fisher Scientific (Leicestershire, United Kingdom). Polyethylene glycol was acquired from Merck Millipore (Darmstadt, Germany). Sodium chloride 0.9\% solution and heparinsodium 5.000 IU/ml were purchased from B. Braun Medical (Queluz de Baixo, Portugal). All of the remaining chemicals were obtained from Sigma-Aldrich unless otherwise stated.

Cell Culture. MDCK II parent cells and transfected MDCK cells with human $M D R 1$ and $A B C G 2$ were obtained from Netherlands Cancer Institute/Antoni van Leeuwenhoek Hospital (Amsterdam, Netherlands). The cells were cultured in Dulbecco's modified Eagle's medium containing 0.04 M sodium bicarbonate and supplemented with $10 \%$ heat-inactivated fetal bovine serum (Gibco Life Technologies brand, ThermoFisher Scientific, Waltham, MA), $100 \mu \mathrm{g} / \mathrm{ml}$ streptomycin, and $100 \mathrm{IU} / \mathrm{ml}$ penicillin. Cells were grown in T-75 flasks (Orange Scientific, Braine-l'Alleud, Belgium), passaged twice a week using a $0.25 \%$ trypsin-EDTA solution and cultured at $37^{\circ} \mathrm{C}$ in $5 \% \mathrm{CO}_{2}$ and $95 \%$ relative humidity. All assays were performed with MDCK II cells from passages 5-14, MDCK-MDR1 cells from passages 6-23, and MDCK-BCRP cells from passages 4-13. The cells were found to be negative for mycoplasma infection in periodic tests.

Cell Viability Studies. The influence of the test compounds on cell viability was determined by 3-(4,5-dimethylthiazol-2-yl)-2,5-diphenyltetrazolium bromide (MTT) assay. MDCK II, MDCK-MDR1, and MDCK-BCRP cells were seeded into 96-well plates (Orange Scientific) at a density of $1 \times 10^{4}$ cells/well and cultured for 24 hours in a humidified incubator at $37^{\circ} \mathrm{C}$ in $5 \% \mathrm{CO}_{2}$ atmosphere. After removing the culture medium, $200 \mu \mathrm{l}$ of fresh medium without (control cells) or with each compound at different concentrations was added to the wells and the cells were incubated for 4 hours $(5-100 \mu \mathrm{M})$ or 30 minutes (only $100 \mu \mathrm{M}$ ). Thereafter, the wells were washed twice with phosphate-buffered saline and the MTT solution $(0.5 \mathrm{mg} / \mathrm{ml})$ was added, followed by incubation for 2 hours at $37^{\circ} \mathrm{C}$ in $5 \% \mathrm{CO}_{2}$. Finally, the MTT solution was removed and replaced with $100 \mu \mathrm{l}$ of DMSO. Absorbance was measured at $570 \mathrm{~nm}$ with a reference wavelength of $620 \mathrm{~nm}$ on a Biotek Synergy HT microplate reader (Biotek Instruments, Winooski, VT).

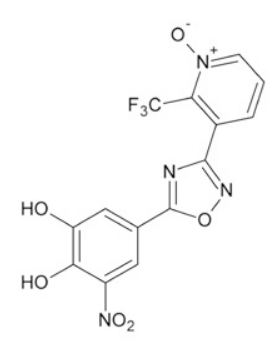

BIA 9-1059

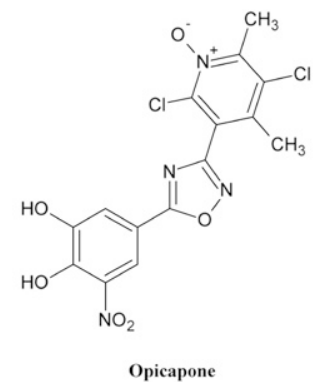

Opicapone<smiles>Cc1nc(Cl)c(-c2noc(-c3cc(O)c(O)c([N+](=O)[O-])c3)n2)c(C)c1Cl</smiles>

BIA 9-1079
Fig. 1. Chemical structures of the analyzed COMT inhibitors.<smiles>CCN(CC)C(=O)/C(C#N)=C/c1cc(O)c(O)c([N+](=O)[O-])c1</smiles><smiles>O=C(Cc1ccccc1)c1cc(O)c(O)c([N+](=O)[O-])c1</smiles> 
Compound concentrations were not considered to compromise cell viability if it was maintained above $85 \%$ compared with control cells (Li et al., 2014).

Stability Studies. Prior to intracellular accumulation and bidirectional transport assays, the stability of COMT inhibitors was evaluated to ensure drug preservation during these assays. Compound solutions were prepared in two concentrations corresponding to low- and high-quality control samples of the respective analytical calibration curve and data were compared before (reference sample) and after (stability sample) exposure to assay conditions [120 minutes, maximum at $37^{\circ} \mathrm{C}$ in Hanks' balanced salt solution (HBSS) with $10 \mathrm{mM}$ HEPES $\mathrm{pH}$ 7.4]. Compounds were considered stable under such conditions when the percentage of the ratio between stability and reference samples was maintained between $85 \%$ and $115 \%$.

Intracellular Accumulation Studies. To assess transporter functionality and identify P-gp and BCRP inhibitors, MDCK II, MDCK-MDR1, and MDCKBCRP were seeded in 12-well plates (Corning Costar, NY) at $3.0 \times 10^{5}$ cells/well for 48 hours. The well-known P-gp or BCRP inhibitors, verapamil and Ko143, respectively, were used as positive controls. The assay was initiated by washing the cells twice with prewarmed HBSS with 10 mM HEPES pH 7.4, followed by an incubation of 30 minutes in the absence (negative control, no inhibitor) or presence of verapamil $(100 \mu \mathrm{M}), \operatorname{Ko} 143(0.5 \mu \mathrm{M})$, or test compound (100 $\mu \mathrm{M}$ in $0.1 \%$ DMSO). Then, compound solutions were removed and the cells were incubated with $10 \mu \mathrm{M}$ rhodamine-123 or Hoechst 33342 as P-gp or BCRP substrates for 1 hour at $37^{\circ} \mathrm{C}$. Cellular accumulation of rhodamine- 123 or Hoechst 33342 was stopped by washing the cells thrice with ice-cold phosphate-buffered saline and cell lysis was performed with Triton X-100 $(0.1 \%$, v/v) at room temperature during 30 minutes. An aliquot of cell lysate was used to measure the amount of accumulated rhodamine-123 or Hoechst 33342 utilizing the Biotek Synergy HT microplate reader (Biotek Instruments) in fluorescence mode (excitation and emission wavelengths of $485 / 528 \mathrm{~nm}$ for rhodamine-123 and $360 / 460 \mathrm{~nm}$ for Hoechst 33342). The protein content of cell lysates was also determined using Bio-Rad Protein Assay Kit II (Bio-Rad Laboratories, Hercules, CA), and cellular accumulation was normalized accordingly. When significant P-gp or BCRP inhibition was observed $(P<0.05)$, additional concentrations of test compounds were evaluated to verify whether the inhibition was concentration dependent, to generate dose-response curves, and to determine the concentration of test compound that inhibits the accumulation of substrate by $50 \%\left(\mathrm{IC}_{50}\right)$.

Bidirectional Transport Studies. For bidirectional transport studies MDCK II, MDCK-MDR1, and MDCK-BCRP were seeded in 12-well polycarbonate microporous Transwell inserts $\left(1.12 \mathrm{~cm}^{2}, 0.4 \mu \mathrm{m}\right.$ pore size; Corning Costar $)$ at a density of $6.0 \times 10^{5}$ cells/well. Assays were conducted 7 days postseeding and culture medium was changed every other day. The transepithelial electrical resistance (TEER) of the polarized cell monolayer was monitored with the Evom STX2 voltohmmeter (WPI, Sarasota, FL). Sodium fluorescein (Na-F) was used as a paracellular marker to attest to the integrity of the cell monolayer during the transport assay and its fluorescence intensity was measured in a microplate reader, as described in the previous section.

Transport studies were performed from the apical (AP)-to-basolateral (BL) (AP-BL) and $\mathrm{BL}$ to $\mathrm{AP}(\mathrm{BL}-\mathrm{AP})$ directions at $37^{\circ} \mathrm{C}$ with gentle shaking ( $\left.45 \mathrm{rpm}\right)$. First, culture medium was replaced with preheated HBSS with $10 \mathrm{mM} \mathrm{HEPES} \mathrm{pH}$ 7.4 and the cells were preincubated for 30 minutes at $37^{\circ} \mathrm{C}$. Then, the donor solution containing the reference or test compound ( $0.1 \%$ DMSO) was added to the $\mathrm{AP}(0.5 \mathrm{ml})$ or BL side $(1.5 \mathrm{ml})$ and the receiver compartment was filled with fresh buffer. Aliquots $(200 \mu \mathrm{l})$ were removed from the receiver side every 15 minutes during 60 minutes for high-permeability compounds or every 30 minutes during 120 minutes for low-permeability compounds. The removed volume was immediately replaced with fresh buffer to maintain compartment volumes and prevent the formation of a hydrostatic pressure gradient. At the end of the incubation period, aliquots were also withdrawn from the donor side to calculate mass balance.

The apparent permeability coefficient $\left(P_{\text {app }}\right)$ of compounds (in centimeters/ second) was calculated using the following equation (Hubatsch et al., 2007):

$$
P_{\mathrm{app}}=\frac{(d Q / d t)}{A \times C_{0}}
$$

where $d Q / d t$ is the rate of permeation; $A$ is the surface area of the membrane (in square centimeters); and $C_{0}$ is the initial drug concentration in the donor compartment.
The efflux ratio (ER) for the BL-AP and AP-BL directions was determined by the following equation:

$$
\mathrm{ER}=\frac{P_{\mathrm{app}, \mathrm{BL}-\mathrm{AP}}}{P_{\mathrm{app}, \mathrm{AP}-\mathrm{BL}}}
$$

The net flux ratios were calculated by dividing the ER obtained in transfected cells by the ER obtained with the parent line MDCK II (Hu et al., 2014). If a net flux ratio over 2 was observed, then verapamil (100 $\mu \mathrm{M}, 30$ minutes) or Ko143 $(0.5 \mu \mathrm{M}, 1$ hour) was added to both sides of the cell monolayer before the donor solutions were added to confirm the specificity of P-gp- or BCRP-mediated efflux.

The mass balance of each compound was calculated according to the following equation:

$$
\text { Mass balance }=\frac{C_{f}^{D} V^{D}+C_{f}^{R} V^{R}}{C_{0}^{D} V^{D}} \times 100
$$

where $C_{f}$ is the final compound concentration in the donor $\left(C_{f}^{D}\right)$ or receiver $\left(C_{f}^{R}\right)$ compartment; $C_{0}$ is the initial concentration in the donor compartment; and $V^{D}$ and $V^{R}$ are the volumes of the donor and receiver compartments, respectively (Hellinger et al., 2012).

Animals. Healthy male Wistar rats weighting 275-300 g were purchased from Charles River Laboratories (L'Arbresle, France). The animals were housed in a controlled environment (12-hour light/dark cycle; temperature $20 \pm 2{ }^{\circ} \mathrm{C}$; relative humidity $55 \% \pm 5 \%$ ) for at least 7 days prior to the beginning of the experiments, with ad libitum access to food and tap water. All experimental and care procedures were conducted in accordance with the European Directive (2010/63/EU) regarding the protection of laboratory animals used for scientific purposes and with the Portuguese law on animal welfare (Decreto-Lei 113/2013). The experimental procedures were reviewed and approved by the Portuguese National Authority for Animal Health, Phytosanitation and Food Safety (Direção Geral de Alimentação e Veterinária, Lisbon).

In Vitro Brain and Plasma Protein Binding. The unbound fraction of BIA 9-1079 and tolcapone in plasma [unbound drug fraction in plasma $\left(\mathrm{f}_{\mathrm{u} \text {,plasma }}\right)$ ] and brain homogenate [unbound drug fraction in the brain $\left(f_{\mathrm{u} \text {,brain }}\right)$ ] were estimated by ultrafiltration, according to Fortuna et al. (2013) with minor alterations. An Amicon Ultra-0.5 centrifugal filter device was used, with a low-binding regenerated cellulose membrane and a $30 \mathrm{KDa}$ cutoff (Merck Millipore). Blank plasma and homogenates of brain tissue collected from healthy Wistar rats $(1 \mathrm{ml})$ were spiked with $10 \mu \mathrm{l}$ of compound solution yielding a final concentration of $100 \mu \mathrm{M}$. Brain homogenates were prepared by dilution with $50 \mathrm{mM}$ phosphatebuffered saline $\mathrm{pH} 7.4(1: 4, \mathrm{w} / \mathrm{v})$ using a Teflon pestle tissue homogenizer (Thomas Scientific, Swedesboro, NJ). At the beginning of the assay, $100 \mu \mathrm{l}$ of plasma or brain homogenate was withdrawn to determine the initial compound concentration $\left(C_{1}\right)$, while the remaining portion was incubated for 1 hour at $37^{\circ} \mathrm{C}$ in a shaking water bath. Following the incubation period, $100 \mu \mathrm{l}$ was collected to determine the concentration of test compound not subjected to ultrafiltration $\left(C_{\mathrm{t}}\right)$ and $500 \mu \mathrm{l}$ was transferred to the ultrafiltration device $(n=4)$ and spun at $14,000 \mathrm{~g}$ for 15 minutes at $37^{\circ} \mathrm{C}$. Then, the concentration of compound was analyzed in the ultrafiltrate $\left(C_{\mathrm{f}}\right)$, in the concentrated sample at the top of the ultrafiltration device $\left(C_{\mathrm{c}}\right)$, and in the remaining sample volume at the end of the experiment $\left(C_{37}\right)$ by HPLC. The unbound fractions $\left(f_{\mathrm{u}}\right)$ in plasma and brain were calculated considering the following equation (Fortuna et al., 2013):

$$
f_{\mathrm{u}}=1-\frac{C_{\mathrm{t}}-C_{\mathrm{f}}}{C_{\mathrm{t}}}
$$

where $C_{\mathrm{t}}$ is the total concentration of compound not subjected to ultrafiltration and $C_{\mathrm{f}}$ is the ultrafiltrate free drug concentration. To correct for the brain tissue dilution that occurs during homogenization, $f_{\text {u,brain }}$ was estimated according to the following equation (Hammarlund-Udenaes, 2014):

$$
f_{\mathrm{u}, \text { brain }}=\frac{1 / D}{\left[\left(1 / f_{\mathrm{u}}\right)-1\right]+1 / D}
$$

where $f_{\mathrm{u}}$ is the fraction of unbound drug in the diluted brain homogenate and $D$ is the dilution factor of brain tissue. The recovery and stability of plasma and brain samples were calculated as follows from eqs. 6 and 7, respectively (Wang and Williams, 2013): 


$$
\begin{gathered}
\% \text { recovery }=\frac{\left(C_{\mathrm{C}} \times V_{\mathrm{C}}+C_{\mathrm{f}} \times V_{\mathrm{f}}\right)}{C_{1 \times} V_{1}} \\
\% \text { stability }=\left(\frac{C_{37}}{C_{1}}\right) \times 100
\end{gathered}
$$

where $C_{1}$ is the initial compound concentration at the beginning of the assay; $V_{1}$ is the volume of plasma or brain homogenate loaded to the ultrafiltration device; $C_{\mathrm{C}}$ and $V_{\mathrm{C}}$ are the drug concentration and volume, respectively, of the sample on the top of the ultrafiltration device at the end of the centrifugation; $C_{\mathrm{f}}$ and $V_{\mathrm{f}}$ are the drug concentration and volume of the ultrafiltrate, respectively; and $\mathrm{C}_{37}$ is the drug concentration at the end of the experiment.

In Vivo Brain Disposition of BIA 9-1079 and Tolcapone. Rats were randomly distributed into two groups, each of which received either BIA 9-1079 $(n=30)$ or tolcapone $(n=27)$. On the day of the experiment, stock solutions of tolcapone and BIA 9-1079 were prepared in DMSO $(40 \mathrm{mg} / \mathrm{ml})$ and diluted 20 -fold in a vehicle composed of polyethylene glycol/ $\mathrm{NaCl} 0.9 \%(50: 50, \mathrm{v} / \mathrm{v})$ to achieve a final concentration of $2 \mathrm{mg} / \mathrm{ml}$. Prior to administration, the animals were anesthetized by intraperitoneal administration of sodium pentobarbital $(60 \mathrm{mg} / \mathrm{kg})$. Under anesthesia, the formulation of tolcapone or BIA 9-1079 was administered by an intravenous bolus injection into the lateral tail vein, at a dose of $10 \mathrm{mg} / \mathrm{kg}$ with a total volume of administration of $5 \mathrm{ml} / \mathrm{kg}$. The dose used in this study was based on literature data (Funaki et al., 1994) and on the requirement of clear solutions appropriate for intravenous administration, dependent on compound solubility. The intravenous route was selected to circumvent intestinal absorption and ensure $100 \%$ bioavailability. For tolcapone, plasma and brain samples were collected immediately after its administration ( 0.03 hour) and at $0.08,0.25,0.5$, $0.75,1,3,6$, and 12 hours postdosing; for BIA 9-1079, an additional sample collection was performed at 24 hours postdosing.

The blood was collected from the left ventricle by cardiac puncture using heparinized syringes and immediately transferred to heparinized tubes for centrifugation at $1514 \mathrm{~g}$ for 10 minutes at $4^{\circ} \mathrm{C}$. Intracardiac perfusion with $\mathrm{NaCl}$ $0.9 \%$ was performed to remove residual blood from brain tissue. The brain was rapidly removed, carefully weighed, and stored frozen at $-80^{\circ} \mathrm{C}$ until drug analysis.

To determine the influence of P-gp and/or BCRP in the transport of BIA 9-1079 and tolcapone, the rats were randomly divided into four groups $(n=8-12$ animals per group), all of which received tolcapone or BIA 9-1079 in the same dose $(10 \mathrm{mg} / \mathrm{kg})$ as in the previous study. In two of the groups, elacridar $(2.5 \mathrm{mg} / \mathrm{kg}$ ) was added to the formulation and coadministered with tolcapone or BIA 9-1079; on the other hand, the other two groups were coadministered with the vehicle [polyethylene glycol/ $\mathrm{NaCl} 0.9 \%(50: 50, \mathrm{v} / \mathrm{v})$ ] instead of elacridar. The animals were sacrificed at $0.08,0.25,0.5$, and 1 hours postdosing and the blood and brain were collected using the aforementioned procedures.

Drug Analysis. Samples collected from the bidirectional transport and protein binding assays, as well as plasma and brain samples from the in vivo studies were analyzed by HPLC with a diode-array detector in the integrated chromatograph model LC-2040C-3D (Shimadzu Corporation, Tokyo, Japan) using validated techniques. Chromatographic analysis was achieved in a LiChroCART Purospher Star-C18 column $(55 \times 4 \mathrm{~mm} ; 3 \mu \mathrm{m}$ particle size from Merck Millipore) by isocratic or gradient elution. Samples from cell-based assays were injected directly or following dilution with HBSS supplemented with $10 \mathrm{mM}$ HEPES pH 7.4, whereas plasma and brain samples of BIA 9-1079 and tolcapone were pretreated according to published methods (Gonçalves et al., 2013, 2016) with minor modifications. Tamoxifen $(90 \mu \mathrm{g} / \mathrm{ml})$ and nebicapone $(35 \mu \mathrm{g} / \mathrm{ml})$ were used as internal standards for plasma and brain samples, respectively. The chromatographic conditions and main validation parameters are summarized in Supplemental Table 1.

Statistical and Pharmacokinetic Data Analysis. Data from in vitro studies were processed using GraphPad Prism 5.03 (GraphPad, San Diego, CA) and are expressed as mean \pm S.D. An unpaired two-tailed Student's $t$ test was used to determine the differences in cell viability (percentage) compared with untreated control cells (100\% cell viability) in the MTT assay and the differences in rhodamine-123 or Hoechst 33342 accumulation compared with negative control cells (no inhibitor) in the intracellular accumulation assay. Differences were considered statistically significant when $* P<0.05$, $* * P<0.01$, and $* * * P<0.001$. The $\mathrm{IC}_{50}$ values were calculated by nonlinear regression generating sigmoid dose-response curves with variable slope, with the fitting method of least squares.
The $C_{\max }$ value in plasma and brain of tolcapone and BIA 9-1079 and the corresponding time to reach $C_{\max }\left(t_{\max }\right)$ were directly obtained from the experimental data. The remaining pharmacokinetic parameters were estimated from the mean concentration values determined at each time point by noncompartmental analysis using the WinNonlin version 6.4 software (Certara, Princeton, NJ). The pharmacokinetic parameters evaluated were the area under the curve (AUC) for the drug AUC concentration-time curve from time zero to the time of the last measurable drug concentration $\left(\mathrm{AUC}_{0-\mathrm{t}}\right)$, which was calculated by the linear trapezoidal rule; the AUC from time zero to infinite was calculated from $\mathrm{AUC}_{0-\mathrm{t}}+\left(C_{\text {last }} / K_{\mathrm{el}}\right)$, where $C_{\text {last }}$ is the last observed concentration and $K_{\mathrm{el}}$ is the apparent elimination rate constant estimated by log-linear regression of the terminal segment of the concentration-time profile; the percentage of AUC extrapolated from $t_{\text {last }}$ to infinity (percentage of extrapolated area under the concentration-time curve), where $\mathrm{t}_{\text {last }}$ is the time of $C_{\text {last }}$; and the apparent terminal elimination half-life $\left(t_{1 / 2 \mathrm{el}}\right)$ and mean residence time.

The unbound ratio of brain-to-plasma concentration $\left(K_{\mathrm{p} \text {,uu }}\right)$ was calculated from the ratio of $\mathrm{AUC}_{0-\mathrm{t}}$ for total brain and plasma concentrations $\left(K_{\mathrm{p}}\right), f_{\mathrm{u} \text {,plasma }}$ and $f_{\text {u,brain, }}$, using eq. 8 (Fridén et al., 2011; Loryan et al., 2014):

$$
K_{\mathrm{p}, \text { uu }}=\frac{K_{\mathrm{p}}}{\left(1 / f_{\mathrm{u}, \text { brain corrected }}\right) \times f_{\mathrm{u}, \text { plasma }}}
$$

where the $f_{\mathrm{u} \text {,brain,corrected }}$ values are the $f_{\mathrm{u} \text {,brain }}$ values corrected for lysosomal trapping using the $\mathrm{pH}$ partitioning model proposed by Fridén et al. 2011). Other parameters such as the predicted unbound cytosolic-to-extracellular drug concentration ratio $\left(K_{\mathrm{p}, \mathrm{uu}, \mathrm{cyto}, \mathrm{pred}}\right)$, the predicted lysosomic-to-cytosolic unbound drug concentration ratio $\left(K_{\mathrm{p} \text {,uu,lyso,pred }}\right)$, the predicted unbound drug intracellularto-extracellular partitioning coefficient $\left(K_{\mathrm{p}, \text { uu,cell,pred }}\right)$, and the predicted volume of distribution of unbound drug in the brain $\left(V_{\mathrm{u}, \text { brain,pred }}\right)$ were also estimated according to Fridén et al. (2011) and Loryan et al. (2014).

\section{Results}

Cellular Viability of MDCK II, MDCK-MDR1, and MDCKBCRP Cells. The MTT assay revealed a significant reduction in cell viability for BIA 9-1079, nebicapone, and tolcapone after a 4-hour incubation period, particularly at $100 \mu \mathrm{M}$. This was most evident for BIA 9-1079, in which a decrease of more than $15 \%$ cell viability was observed at concentrations higher than or equal to $20 \mu \mathrm{M}$ in MDCKMDR1 cells $(P<0.01), 50 \mu \mathrm{M}$ in MDCK-MDR1 $(P<0.001)$, and MDCK-BCRP cells $(P<0.01)$ and at 80 and $100 \mu \mathrm{M}$ in all cell lines ( $P=0.002$ for MDCK II at $80 \mu \mathrm{M}$ or $<0.001$ in the remaining cases). Concerning nebicapone, MDCK-MDR1 cells were affected at $80 \mu \mathrm{M}$ $(P<0.05)$ and $100 \mu \mathrm{M}(P<0.001)$. Furthermore, a decrease was also observed for tolcapone at 50, 80, and $100 \mu \mathrm{M}$ in MDCK-MDR1 cells $(P<0.01)$ and at $100 \mu \mathrm{M}$ in MDCK-BCRP cells $(P<0.01)$. Hence, the incubation period was shortened to 30 minutes for the duration of the incubation period in intracellular accumulation assays, and no significant loss of cell viability $(P>0.05)$ was verified at $100 \mu \mathrm{M}$ in all cell lines. For studies exceeding 30 minutes (i.e., bidirectional transport assay) the selected concentration for these test compounds was $10 \mu \mathrm{M}$.

Stability of COMT Inhibitors. During 120 minutes, stability at $37^{\circ} \mathrm{C}$ in HBSS with $10 \mathrm{mM}$ HEPES pH 7.4 was kept in the range of $85 \%-115 \%$ for all compounds with the exception of BIA 9-1079 (Supplemental Table 2), in which significant reductions in the average stability values under $85 \%$ were observed at lower concentrations (lowquality control samples) after 90 minutes. These results were taken into consideration in association with data from the MTT studies when defining the maximal duration of subsequent assays.

Intracellular Accumulation of Rhodamine-123 and Hoechst33342 in MDCK II, MDCK-MDR1, and MDCK-BCRP Cells. As presented in Fig. 2A and B, the functionality of P-gp and BCRP was confirmed through a significantly lower uptake of rhodamine-123 and Hoechst 33342 in MDCK-MDR1 and MDCK-BCRP cells compared with the parent line MDCK II. The addition of a P-gp $(100 \mu \mathrm{M}$ 
A

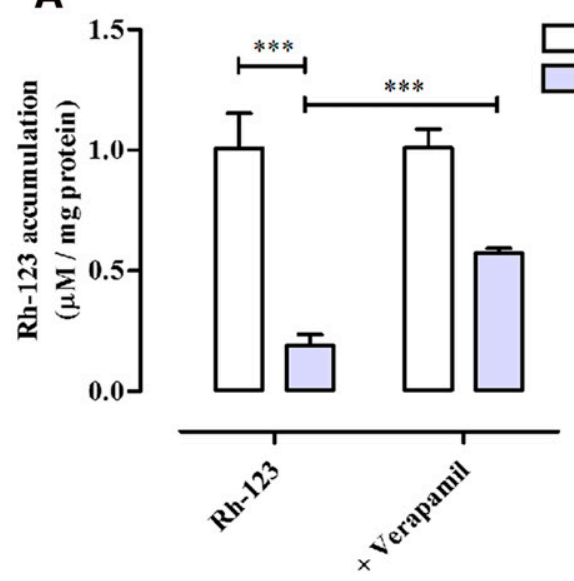

MDCK II MDCK-MDR1

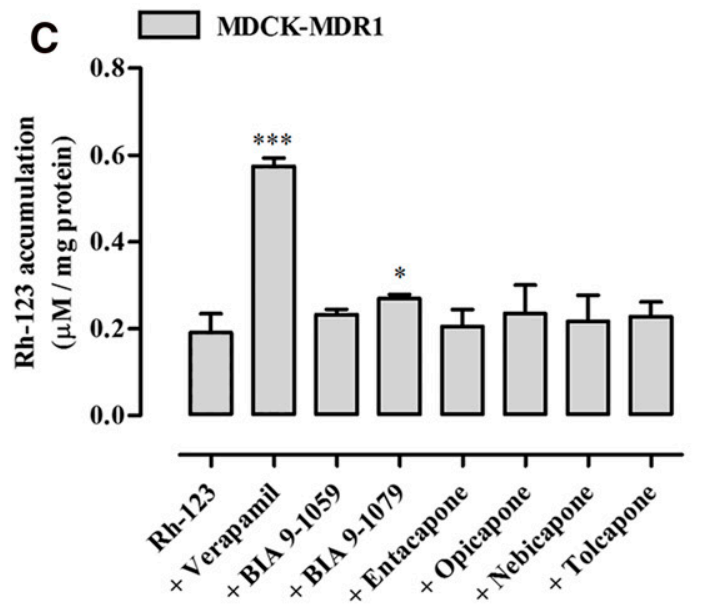

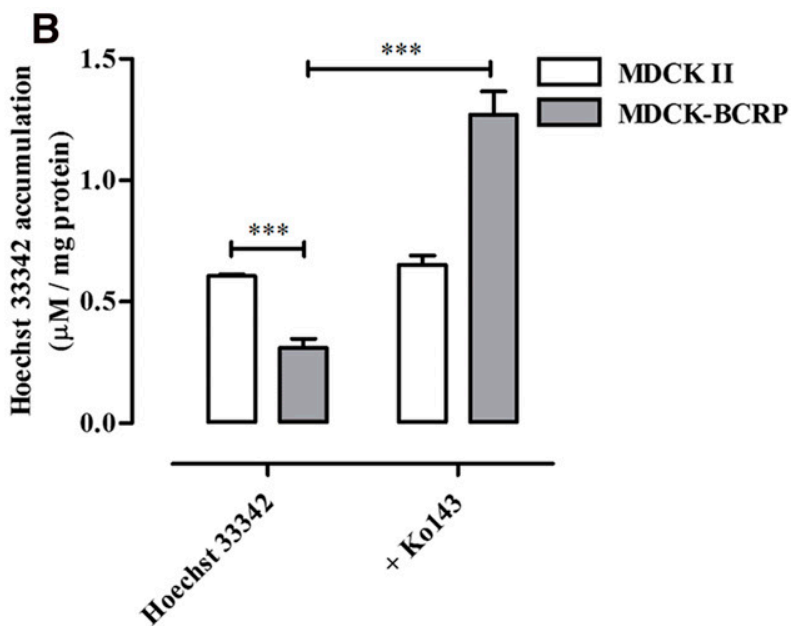

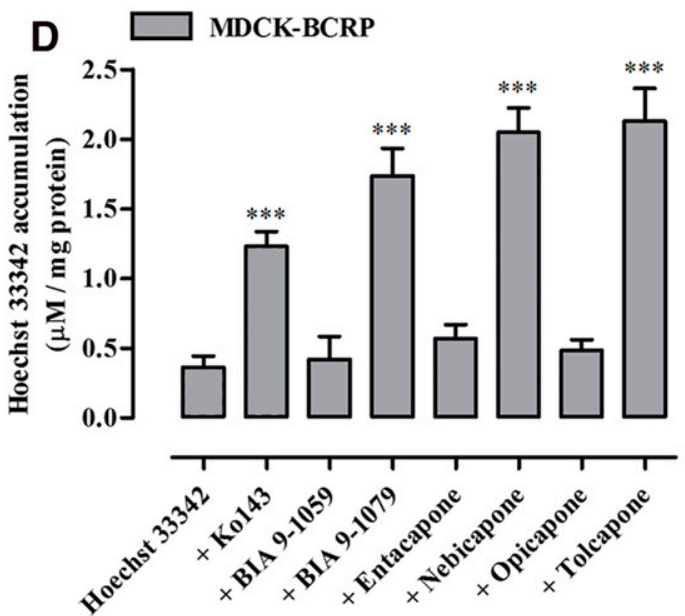

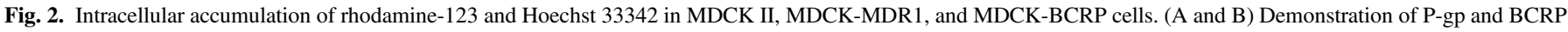

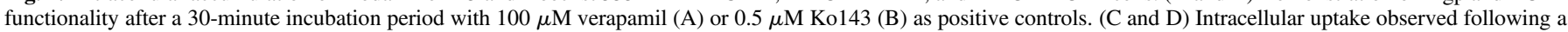

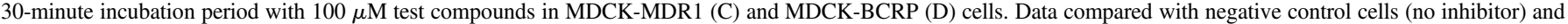
expressed as mean \pm S.D. $(n=3)$. ${ }^{*} P<0.05 ; * * P<0.01$; *** $P<0.001$.

verapamil) or BCRP inhibitor $(0.5 \mu \mathrm{M}$ Ko143) reversed this tendency and led to increased accumulation of classic substrates (rhodamine-123 and Hoechst 33342) in both cases (by 3.0- and 4.2-fold, respectively). In contrast, as expected no inhibitory effect was observed in MDCK II cells.

Incubation of MDCK-MDR1 and MDCK-BCRP cells with $100 \mu \mathrm{M}$ test compounds revealed a significant accumulation of rhodamine-123 or Hoechst 33342 for some compounds in relation to negative controls (no addition of inhibitor) (Fig. 2C and D). Since BIA 9-1079 significantly inhibited P-gp in MDCK-MDR1 cells, additional concentrations were tested, which detected concentration-dependent inhibition. Nevertheless, the $\mathrm{IC}_{50}$ value of BIA 9-1079 could not be experimentally determined because it would be necessary to test concentrations over $100 \mu \mathrm{M}$ to reach the top inhibition plateau, which would compromise solubility and the accuracy of the results. In MDCK-BCRP cells, further concentrations of BIA 9-1079, nebicapone, and tolcapone (Fig. 3A-C) were tested since a very significant BCRP inhibition was observed at $100 \mu \mathrm{M}$ (Fig. 2D). The lowest $\mathrm{IC}_{50}$ value was obtained for BIA 9-1079 $\left(\mathrm{IC}_{50}=3.85 \pm 1.0 \mu \mathrm{M}\right)$, followed by nebicapone $\left(\mathrm{IC}_{50}=18.4 \pm 3.6\right.$ $\mu \mathrm{M})$ and tolcapone $\left(\mathrm{IC}_{50}=32.5 \pm 3.3 \mu \mathrm{M}\right)$.

Transport of COMT Inhibitors across MDCK II, MDCKMDR1, and MDCK-BCRP Monolayers. The assessment of monolayer integrity was carried out through the monitorization of TEER and $P_{\text {app }}$ determination of the paracellular marker Na-F. These parameters ensure that the established model is adequate for drug permeation studies by presenting sufficiently restrictive tight junctions that impede paracellular permeation identically to the in vivo situation (Abbott et al., 2014). Although registered TEER values were approximately $100 \Omega \cdot \mathrm{cm}^{2}$ for all cell lines, which could be interpreted as an indicator of leaky monolayers, MDCK II cells are known to display low TEER values (Dukes et al., 2011) due to ion movement through ion pores (Hellinger et al., 2012). Thus, low TEER does not necessarily imply disturbed paracellular pathways if there is integrity for paracellular marker molecules. Small tracer molecules, such as Na-F are suggested to be used to assess the paracellular permeability of tighter layers (Abbott et al., 2014). Herein, the $P_{\text {app }}$ of Na-F was inferior to $1.0 \times 10^{-6} \mathrm{~cm} / \mathrm{s}$ in MDCK II cells and $0.5 \times 10^{-6} \mathrm{~cm} / \mathrm{s}$ in MDCK-MDR1 and MDCKBCRP cells (Table 1), supporting the formation of a discriminatory cell monolayer. The $P_{\text {app }}$ values below $1-2 \times 10^{-6} \mathrm{~cm} / \mathrm{s}$ are indicative of monolayer intactness (Ehlers et al., 2014). Another estimated parameter in this assay was mass balance, which was between $80 \%$ and $100 \%$ for less lipophilic compounds and between $70 \%$ and $80 \%$ for more lipophilic compounds.

The concentration of donor solutions and the sampling time of each reference and test compound were defined following preliminary assays and considering the sensitivity of the analytical methods, as well as the data from cell viability and stability studies. Prior to transport studies 
A

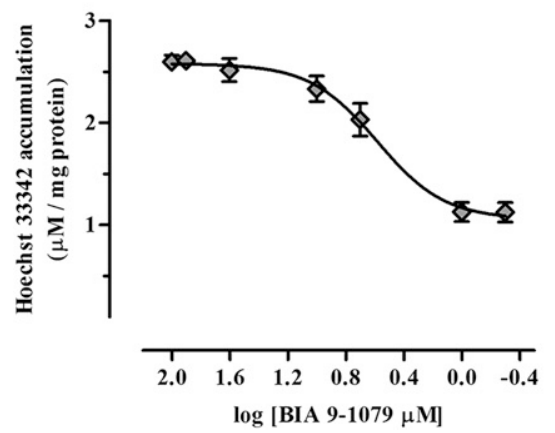

B
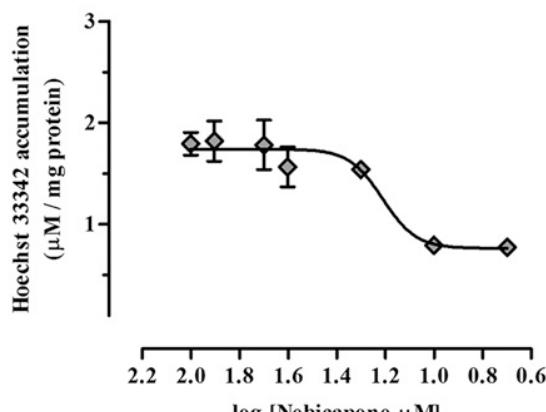

C
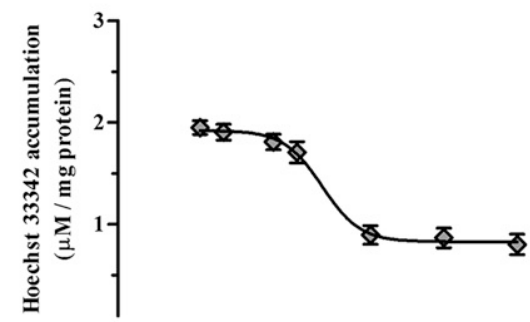

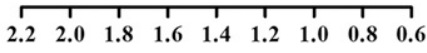

$\log$ [Tolcapone $\mu \mathrm{M}$ ]

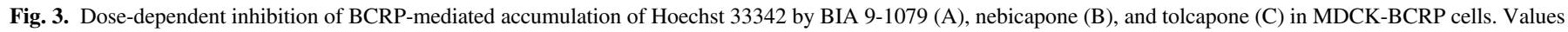
represent mean \pm S.D. $(n=3)$.

with COMT inhibitors, a set of seven chemically diversified commercial drugs was used to validate the experimental conditions (Table 1). The net flux ratios of respective P-gp and BCRP substrates were higher than 2, which verified the correct identification by the respective transporter, and the achieved results were consistent with the literature data, demonstrating that the applied method provides enough sensitivity for the identification of P-gp and BCRP substrates.

Among the tested COMT inhibitors, BIA 9-1079 was identified as a P-gp substrate (Table 2) with a net flux ratio reduced more than $50 \%$ by verapamil $(78.7 \% \pm 10.3 \%)$, attesting to the specificity of P-gpmediated efflux. In parallel, BIA 9-1059, entacapone, nebicapone, and opicapone were, for the first time, identified as BCRP substrates. After preincubation with Ko143, a decrease in the net flux ratio of $89.7 \% \pm$ $2.18 \%$ was obtained for BIA 9-1059, with decreases of $91.1 \% \pm 2.47 \%$, $64.2 \% \pm 3.96 \%$, and $91.2 \% \pm 1.90 \%$ obtained for entacapone, nebicapone, and opicapone, respectively. The detection of net flux ratios higher than 2 together with a reduction of over $50 \%$ in the presence of an inhibitor, ascertain the identification of COMT inhibitors as P-gp and/or BCRP substrates in accordance with the decision trees provided by the International Transporter Consortium and Food and Drug Administration (Giacomini et al., 2010; Food and Drug Administration, 2012).

Binding of BIA 9-1079 and Tolcapone to Plasma and Brain Tissue. The obtained values of $f_{\mathrm{u} \text {,plasma }}$ and $f_{\mathrm{u} \text {,brain }}$ for BIA 9-1079 and tolcapone following ultrafiltration are indicated in Table 4. Both COMT inhibitors revealed high binding to plasma proteins in in vitro conditions, with recoveries ranging from $86.1 \% \pm 1.8 \%$ (BIA 9-1079) to $96.0 \% \pm 10.6 \%$ (tolcapone) and stability values of $105.9 \% \pm 3.0 \%$ and $102.2 \pm 2.5 \%$, respectively. Uncorrected and corrected $f_{\mathrm{u} \text {,brain }}$ values were lower for BIA 9-1079 than tolcapone with recoveries of $97.3 \% \pm$ $3.1 \%$ for BIA $9-1079$ and $91.9 \% \pm 3.07 \%$ for tolcapone. Stability values were $100.2 \% \pm 5.0 \%$ and $86.0 \% \pm 1.4 \%$ for BIA 9-1079 and tolcapone.

Plasma and Brain Pharmacokinetics of BIA 9-1079 and Tolcapone. The mean concentration-time profiles of BIA 9-1079 and tolcapone in plasma and brain after a single intravenous dose $(10 \mathrm{mg} / \mathrm{kg})$ to rats are depicted in Fig. 4A and B. The main pharmacokinetic parameters estimated by noncompartmental analysis and other pharmacokinetic parameters relative to the extent and intrabrain distribution are presented in Table 3 and 4. Considering the pharmacokinetic profiles of both compounds in plasma (Fig. 4A), it is visible that the systemic exposure of BIA 9-1079 is greater than that of tolcapone, as corroborated by the area under the concentration-time curve from time zero to infinite, which was 2.3-fold higher for BIA 9-1079. The 4.0-fold higher $t_{1 / 2 \mathrm{el}}(5.39$ versus 1.36 hours) demonstrates that BIA 9-1079 was more slowly eliminated and remained longer in plasma than tolcapone (2.46 hours versus 1.09 hours).

In opposition, brain exposure was 3.3-fold higher for tolcapone than for BIA 9-1079, considering the $\mathrm{AUC}_{0-\mathrm{t}}$ values. The $C_{\max }$ value in the brain was also 2.1-fold higher for tolcapone and was reached almost immediately after administration ( 0.03 hour). Nonetheless, the obtained $K_{\mathrm{p}, \mathrm{uu}}$ values were below unit for both compounds, indicating a restricted extent of brain

TABLE 1

Bidirectional $P_{\text {app }}$ coefficient, ER, and net flux ratio of reference compounds across MDCK II, MDCK-MDR1, and MDCK-BCRP cell monolayers

The $\mathrm{P}_{\text {app }}$ values are indicated from the AP-BL and BL-AP compartments and are expressed as mean (S.D.) (n = 3). ERs and net flux ratios greater than 2 are marked in bold. Transport classification according to Mahar Doan et al. (2002), Pavek et al. (2005), Wang et al. (2005), Feng et al. (2008), and Urquhart et al. (2008).

\begin{tabular}{|c|c|c|c|c|c|c|c|c|c|c|c|c|c|c|c|}
\hline \multirow{2}{*}{$\begin{array}{l}\text { Reference } \\
\text { Compound }\end{array}$} & \multirow{2}{*}{ Transport } & \multirow{2}{*}{$\begin{array}{l}\text { Donor } \\
\text { Solution }\end{array}$} & \multicolumn{3}{|c|}{ MDCK II } & \multicolumn{3}{|c|}{ MDCK-MDR1 } & \multicolumn{2}{|c|}{ Net Flux Ratio } & \multicolumn{3}{|c|}{ MDCK-BCRP } & \multicolumn{2}{|c|}{ Net Flux Ratio } \\
\hline & & & $\begin{array}{c}P_{\text {app,AP-BL }} \\
\left(\times 10^{-6}\right)\end{array}$ & $\begin{array}{l}P_{\text {app,BL-AP }} \\
\left(\times 10^{-6}\right)\end{array}$ & ER & $\begin{array}{l}P_{\text {app,AP-BL }} \\
\left(\times 10^{-6}\right)\end{array}$ & $\begin{array}{l}P_{\text {app,BL-AP }} \\
\left(\times 10^{-6}\right)\end{array}$ & ER & $\begin{array}{l}\text { Without } \\
\text { Verapamil }\end{array}$ & $\begin{array}{c}\text { With } \\
\text { Verapamil }\end{array}$ & $\begin{array}{l}P_{\text {app,AP-BL }} \\
\left(\times 10^{-6}\right)\end{array}$ & $\begin{array}{l}P_{\text {app,BL-AP }} \\
\left(\times 10^{-6}\right)\end{array}$ & ER & $\begin{array}{l}\text { Without } \\
\text { Ko143 }\end{array}$ & $\begin{array}{c}\text { With } \\
\text { Kol43 }\end{array}$ \\
\hline & & $\mu M$ & $\mathrm{~cm} / \mathrm{s}$ & $\mathrm{cm} / \mathrm{s}$ & & $\mathrm{cm} / \mathrm{s}$ & $\mathrm{cm} / \mathrm{s}$ & & & & $\mathrm{cm} / \mathrm{s}$ & $\mathrm{cm} / \mathrm{s}$ & & & \\
\hline Carbamazepine & PT & 10 & $36.5(1.93)$ & $19.5(0.60)$ & 0.53 & $38.0(2.54)$ & $20.0(5.53)$ & 0.53 & 1.00 & - & $37.3(5.60)$ & $19.6(3.85)$ & 0.53 & 1.00 & - \\
\hline Propranolol & PT & 10 & $19.6(4.99)$ & $20.0(0.16)$ & 1.02 & $23.8(2.69)$ & $20.8(1.51)$ & 0.87 & 0.85 & - & $25.4(2.51)$ & $22.4(0.59)$ & 0.88 & 0.86 & - \\
\hline Trazodone & PT & 10 & $38.5(3.30)$ & $29.4(1.31)$ & 0.76 & $33.0(2.58)$ & $40.4(3.14)$ & 1.22 & 1.61 & - & $37.5(5.03)$ & $27.4(2.91)$ & 0.73 & 0.96 & - \\
\hline Atenolol & PP & 100 & $0.22(0.06)$ & $0.28(0.03)$ & 1.27 & $0.35(0.14)$ & $0.24(0.04)$ & 0.69 & 0.54 & - & $0.14(0.11)$ & $0.20(0.03)$ & 1.43 & 1.13 & - \\
\hline Cimetidine & Efflux $^{a}$ & 30 & $0.56(0.14)$ & $0.43(0.03)$ & 0.75 & $0.06(0.02)$ & $0.41(0.05)$ & 6.40 & 8.50 & 0.89 & $0.15(0.04)$ & $1.25(0.08)$ & 8.34 & 11.1 & 1.47 \\
\hline Quinidine & Efflux $^{b}$ & 10 & $9.52(2.53)$ & $12.5(2.49)$ & 1.31 & $3.77(0.91)$ & $29.1(1.37)$ & 7.73 & 5.90 & 1.13 & $12.0(3.48)$ & $15.0(0.48)$ & 1.25 & 0.95 & - \\
\hline Sulfasalazine & Efflux $^{c}$ & 60 & $0.81(0.30)$ & $0.28(0.05)$ & 0.34 & $0.30(0.14)$ & $0.17(0.09)$ & 0.56 & 1.64 & - & $0.13(0.11)$ & $0.30(0.05)$ & 2.31 & 6.79 & 0.92 \\
\hline $\mathrm{Na}-\mathrm{F}$ & $\mathrm{PP}$ & 100 & $0.48(0.09)$ & - & - & $0.09(0.08)$ & - & - & - & - & $0.11(0.04)$ & - & - & - & - \\
\hline
\end{tabular}

PP, passive paracellular; PT, passive transcellular.

${ }^{a}$ Efflux mediated by P-gp and BCRP.

${ }^{b}$ Efflux mediated by P-gp.

${ }^{c}$ Efflux mediated by BCRP. 
TABLE 2

The $P_{\text {app }}$ coefficient values, ER, and net flux ratio of COMT inhibitors across MDCK II, MDCK-MDR1, and MDCK-BCRP cell monolayers

The $\mathrm{P}_{\text {app }}$ values are indicated from the AP-BL and BL-AP compartments and are expressed as mean (S.D.) ( $\mathrm{n}=3$ ). ERs and net flux ratios greater than 2 are marked in bold.

\begin{tabular}{|c|c|c|c|c|c|c|c|c|c|c|c|c|c|c|}
\hline \multirow{2}{*}{$\begin{array}{c}\text { Test } \\
\text { Compound }\end{array}$} & \multirow{2}{*}{$\begin{array}{c}\text { Donor } \\
\text { Solution }\end{array}$} & \multicolumn{3}{|c|}{ MDCK II } & \multicolumn{3}{|c|}{ MDCK-MDR1 } & \multicolumn{2}{|c|}{ Net Flux Ratio } & \multicolumn{3}{|c|}{ MDCK-BCRP } & \multicolumn{2}{|c|}{ Net Flux Ratio } \\
\hline & & $\begin{array}{l}P_{\text {app,AP-BL }} \\
\left(\times 10^{-6}\right)\end{array}$ & $\begin{array}{l}P_{\text {app,BL-AP }} \\
\left(\times 10^{-6}\right)\end{array}$ & ER & $\begin{array}{l}P_{\text {app,AP-BL }} \\
\left(\times 10^{-6}\right)\end{array}$ & $\begin{array}{l}P_{\text {app,BL-AP }} \\
\left(\times 10^{-6}\right)\end{array}$ & ER & $\begin{array}{l}\text { Without } \\
\text { Verapamil }\end{array}$ & $\begin{array}{c}\text { With } \\
\text { Verapamil }\end{array}$ & $\begin{array}{l}P_{\text {app,AP-BL }} \\
\left(\times 10^{-6}\right)\end{array}$ & $\begin{array}{l}P_{\text {app,BL-AP }} \\
\left(\times 10^{-6}\right)\end{array}$ & ER & $\begin{array}{l}\text { Without } \\
\text { Ko143 }\end{array}$ & $\begin{array}{c}\text { With } \\
\text { Ko143 }\end{array}$ \\
\hline & $\mu M$ & $\mathrm{~cm} / \mathrm{s}$ & $\mathrm{cm} / \mathrm{s}$ & & $\mathrm{cm} / \mathrm{s}$ & $\mathrm{cm} / \mathrm{s}$ & & & & $\mathrm{cm} / \mathrm{s}$ & $\mathrm{cm} / \mathrm{s}$ & & & \\
\hline BIA 9-1059 & 60 & $1.29(0.27)$ & $1.47(0.18)$ & 1.14 & $1.22(0.23)$ & $0.35(0.07)$ & 0.29 & 0.25 & - & $0.24(0.08)$ & $1.69(0.44)$ & 7.04 & 6.18 & 0.64 \\
\hline BIA 9-1079 & 10 & $5.23(2.75)$ & $8.47(0.91)$ & 1.62 & 3.47 (1.77) & $15.9(4.19)$ & 4.58 & 2.83 & 0.60 & $7.14(4.63)$ & $13.6(1.74)$ & 1.90 & 1.17 & - \\
\hline Entacapone & 30 & $6.33(0.37)$ & $6.02(0.39)$ & 0.95 & $3.51(1.33)$ & $1.29(0.36)$ & 0.37 & 0.39 & - & $0.98(0.19)$ & $11.1(0.92)$ & 11.3 & 11.9 & 1.06 \\
\hline Nebicapone & 10 & $24.6(1.45)$ & $17.6(4.18)$ & 0.72 & $23.9(7.06)$ & $14.3(2.60)$ & 0.60 & 0.83 & - & $5.40(0.09)$ & $11.6(0.63)$ & 2.15 & 2.99 & 1.07 \\
\hline Opicapone & 30 & $4.72(2.33)$ & $6.08(0.38)$ & 1.29 & $2.56(1.08)$ & $2.50(0.39)$ & 0.98 & 0.76 & - & $0.42(0.09)$ & $9.73(1.13)$ & 23.2 & 18.0 & 1.58 \\
\hline Tolcapone & 10 & $26.6(5.07)$ & $20.6(3.87)$ & 0.77 & $24.3(2.84)$ & $19.5(3.37)$ & 0.80 & 1.04 & - & $28.3(2.93)$ & $23.7(1.65)$ & 0.84 & 1.09 & - \\
\hline
\end{tabular}

penetration and dominant active efflux processes. As previously mentioned, this parameter was determined from $K_{\mathrm{p}}$ and in vitro $f_{\mathrm{u} \text {,brain }}$ converted to $f_{\mathrm{u} \text {,brain,corrected }}$ according to Fridén et al. (2011). To determine $f_{\text {u,brain, }}$ corrected, it was required to estimate $K_{\mathrm{p} \text {,uu,cell,pred }}$ by taking into account the $\mathrm{p} K_{\mathrm{a}}$ value of the drug. Despite possessing two $\mathrm{p} K_{\mathrm{a}}$ values (4.9 and 10.2 for BIA 9-1079; 3.1 and 9.9 for tolcapone), both compounds were herein considered acids due to the net negative charge displayed at $\mathrm{pH}$ 7.4. The observed $K_{\mathrm{p} \text {,uu,cell,pred }}$ values (Table 4 ) reflect a low intracellular accumulation of the compounds and exclude trapping in lysosomes, as well as uptake into cells. From $f_{\mathrm{u} \text {,brain,corrected }}$ and $V_{\mathrm{u} \text {,brain,pred }}\left(=1 / f_{\mathrm{u} \text {,brain,corrected }}\right)$ it is noticeable that both compounds reveal nonspecific binding to brain parenchyma $\left(V_{\mathrm{u}, \text { brain,pred }}>0.8 \mathrm{ml} / \mathrm{g}\right.$ brain); although this is more evident for BIA 9-1079 than tolcapone because tolcapone displays a higher $f_{\mathrm{u} \text {,brain, }}$ corrected (0.247), and is therefore more available for target engagement than BIA 9-1079. Brain tissue binding is also influenced by lipophilicity and even though both compounds are moderately lipophilic BIA 9-1079 is more lipophilic $(\log \mathrm{D} \mathrm{pH} 7.4=1.7)$ than tolcapone $(\log \mathrm{D} \mathrm{pH} 7.4=0.1)$, originating a higher affinity of BIA 9-1079 to brain components.
The effect of the coadministration of elacridar on the plasma and brain concentration-time profiles of tolcapone and BIA 9-1079 are depicted in Fig. 4C-F. The proximity evidenced in Fig. $4 \mathrm{C}$ and $\mathrm{E}$ between plasma concentrations after vehicle or elacridar administration and the $\mathrm{AUC}_{0-\mathrm{t}}$ values of BIA 9-1079 or tolcapone with vehicle or with elacridar (Table 5) suggests that plasma exposure was not affected by the coadministration of elacridar. Nevertheless, statistically significant differences were found in brain concentrations of BIA 9-1079 and tolcapone between elacridar and vehicle-administered rats, namely, at $0.25,0.5$, and 1 hours postdosing (Fig. 4D and F). With elacridar, the brain $\mathrm{AUC}_{0-\mathrm{t}}$ values of BIA 9-1079 and tolcapone increased 2.57- and 2.38-fold, respectively. These results attest the contribution of P-gp and/or BCRP to the limited extent of brain distribution of these COMT inhibitors.

\section{Discussion}

The BBB is a dynamic interface responsible for the homeostasis of the CNS through the regulation of the molecular exchanges between the
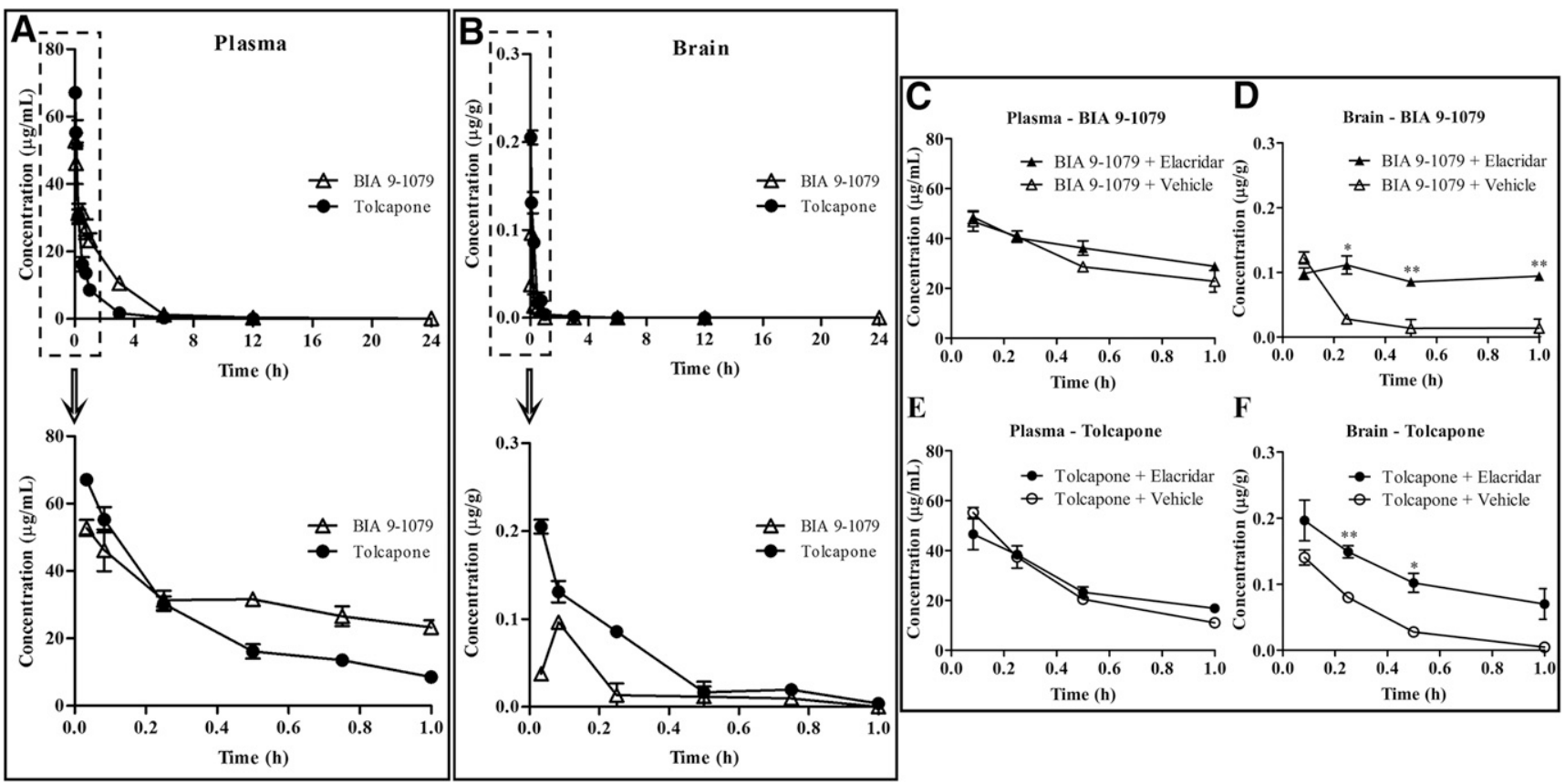

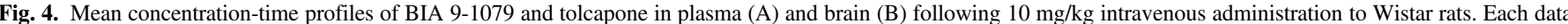

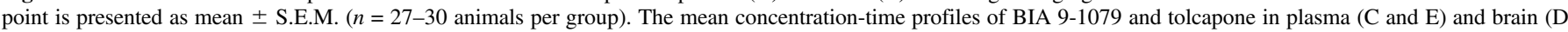

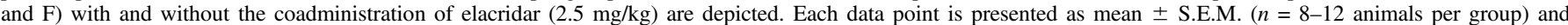
significant differences between group concentrations at specific time points were calculated by two-tailed Student's $t$ test. $* P<0.05$; $* * P<0.01$. 
TABLE 3

Pharmacokinetic parameters of BIA 9-1079 and tolcapone in plasma and brain after intravenous administration $(10 \mathrm{mg} / \mathrm{kg})$ to Wistar rats

The $\mathrm{C}_{\text {max }}$ values are expressed in micrograms/gram and the AUC is expressed in micrograms. hour/gram in brain tissue.

\begin{tabular}{lcccccccc}
\hline Test Compound & $t_{\max }$ & $C_{\max }$ & $\mathrm{AUC}_{0-\mathrm{t}}$ & $\mathrm{AUC}_{0-\text { inf }}$ & $\mathrm{AUC}_{\mathrm{extrap}}$ & $K_{\mathrm{el}}$ & $t_{1 / 2 \mathrm{el}}$ & $\mathrm{MRT}$ \\
\hline & $h$ & $\mu g / m l$ & $\mu g . h / m l$ & $\mu g . h / m l$ & $\%$ & $h$ & $h$ & $h$ \\
BIA 9-1079 & & & & & & & & \\
$\quad$ Plasma & 0.03 & 52.78 & 84.08 & 84.94 & 1.02 & 0.13 & 5.39 & 2.46 \\
$\quad$ Brain & 0.08 & 0.096 & 0.017 & $\mathrm{NC}$ & $\mathrm{NC}$ & 0.66 & 1.05 & 0.23 \\
Tolcapone & & & & & & & & \\
$\quad$ Plasma & 0.03 & 67.12 & 36.24 & 36.28 & 0.10 & 0.51 & 1.36 & 1.09 \\
$\quad$ Brain & 0.03 & 0.205 & 0.056 & 0.057 & 1.79 & 1.53 & 0.45 & 0.38
\end{tabular}

$\mathrm{AUC}_{\text {extrap}}$, extrapolated area under the concentration-time curve; $\mathrm{AUC}_{0 \text {-inf }}$, area under the concentration-time curve from time zero to infinite; $\mathrm{AUC}_{0-\mathrm{t}}$, area under the concentration-time curve from time zero to the last measurable concentration; $K_{\mathrm{el}}$, apparent elimination rate constant; MRT, mean residence time; NC, not calculated; $t_{1 / 2 \mathrm{el}}$, apparent terminal elimination half-life; $t_{\max }$, time to achieve the maximum concentration.

blood and neural tissue. Its complex microenvironment creates a severely restricted traffic of molecules into the CNS and makes the evaluation of CNS exposure during drug development a very challenging task. This assessment encompasses not only the rate of drug transport across the BBB, but also the extent of equilibration of unbound drug and intrabrain distribution. Using in vitro models, it is possible to investigate the permeability of compounds early on, as well as the interactions with efflux transporters that affect their extent of CNS penetration in vivo, namely, P-gp and BCRP. Despite having different morphologic characteristics from brain endothelial cells, MDCK cells and transfected subclones have been widely used to study permeability and efflux liabilities mediated by the main efflux transporters of the BBB, P-gp and BCRP. In addition to displaying BBB-like permeability, these cells effectively identify a great number of efflux substrates (Garberg et al., 2005; Hellinger et al., 2012). Indeed, bidirectional transport assays with MDCK-MDR1 cells have been reported as a valuable in vitro assay to evaluate human P-gp interactions with compounds targeted to treat CNS disorders (Feng et al., 2008), and these systems are recommended by the International Transporter Consortium to investigate if active efflux by these transporters prevents a compound from crossing the BBB (Brouwer et al., 2013). Therefore, the MDCK II, MDCK-MDR1, and MDCK-BCRP cell lines were selected to examine the influence of P-gp and BCRP on the access of COMT inhibitors to the CNS. Another aspect that was investigated in vitro was whether these compounds could inhibit the P-gp- or BCRP-mediated efflux of known fluorescent probe substrates (rhodamine-123 and Hoechst 33342).

In the intracellular accumulation assay, reference P-gp (verapamil) and BCRP (Ko143) inhibitors successfully prevented the efflux of rhodamine-123 or Hoescht 33342 in MDCK-MDR1 and MDCK-BCRP cells, respectively. Care was taken to use Ko143 at $0.5 \mu \mathrm{M}$ in all assays due to the recently reported lack of BCRP specificity for concentrations above $1 \mu \mathrm{M}$ (Weidner et al., 2015). Among COMT inhibitors, BIA 9-1079, nebicapone, and tolcapone demonstrated concentrationdependent inhibition of $\mathrm{BCRP}$, and the $\mathrm{IC}_{50}$ values indicate that BIA 9-1079 was the most potent BCRP inhibitor among the test compounds. However, the observed inhibitory effect was not considered clinically relevant and a drug-drug interaction risk at the BBB is low since the circulating levels of this compound are 30 times lower in plasma than the reported concentrations that result in inhibition of BCRP. According to Almeida et al. (2013) the maximum concentration obtained in plasma for BIA 9-1079 after a single therapeutic oral dose of $50 \mathrm{mg} /$ person of opicapone was $51 \mathrm{ng} / \mathrm{ml}$, while the $\mathrm{IC}_{50}$ value herein found was $3.85 \mu \mathrm{M}$ (approximately $1530 \mathrm{ng} / \mathrm{ml}$ ). Thus far, the most potent inhibitors capable of affecting efflux at the BBB in humans and nonhuman primates are tariquidar and elacridar (Bauer et al., 2013, 2016; Montesinos et al., 2014; Tournier et al., 2017); nevertheless, these inhibitors are only available for research. For marketed drugs, modulation of efflux at the BBB is deemed improbable because the unbound systemic concentrations attained at therapeutic doses are low, meaning that major increases in brain uptake are not usually observed in the presence of clinically relevant doses of the inhibitor (Kalvass et al., 2013).

In transcellular permeability assays it was possible to identify one P-gp substrate (BIA 9-1079) and four BCRP substrates (BIA 9-1059, entacapone, nebicapone, and opicapone) among COMT inhibitors. Notwithstanding, the contribution of P-gp- and BCRP-mediated efflux to the overall distribution of compounds across the BBB should be conjugated with information regarding other aspects that affect CNS exposure and/or activity in vivo.

Thereby, BIA 9-1079 and tolcapone were herein administered to Wistar rats and the pharmacokinetic parameters obtained in the brain support that both compounds crossed the BBB quickly and soon achieved $C_{\max }$. This is in accordance with their high $P_{\text {app,AP-BL values }}$ attained in vitro. Still, the most clinically relevant parameter, $K_{\mathrm{p}, \mathrm{uu}}$, revealed a low extent of brain penetration for both compounds, and in particular for BIA 9-1079. These results were not surprising for BIA 9-1079 given that it had been identified as a P-gp substrate in vitro. Notwithstanding, tolcapone was not identified in vitro as a P-gp or BCRP substrate, probably because of its very high permeability masking its efflux transport. In fact, this has also been observed for other high permeability efflux substrates, such as verapamil, meaning that the involved efflux transporter(s) was (or were) unable to cope with compound permeation (Hellinger et al., 2012). This is a limitation of the bidirectional transport assay that may prevent compounds with a

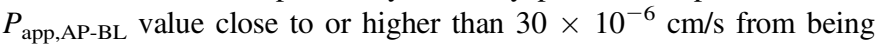
identified as efflux substrates (Polli et al., 2001; Gameiro et al., 2017), emphasizing the importance of performing in vivo studies for such compounds. Even though nebicapone displayed a similarly high passive permeability, the $P_{\text {app }}$ values for tolcapone were consistently higher in

TABLE 4

Pharmacokinetic parameters and binding data of BIA 9-1079 and tolcapone in plasma and brain after intravenous administration (10 mg/kg) to Wistar rats

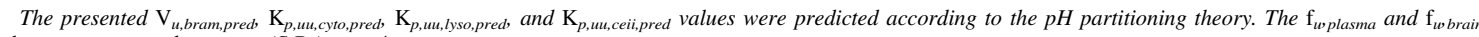
values are expressed as mean (S.D.), $\mathrm{n}=4$.

\begin{tabular}{lccccccccc}
\hline Test Compound & $K_{\mathrm{p}}$ & $f_{\text {u,plasma }}$ & $f_{\text {u,brain }}$ & $f_{\text {u,brain,corrected }}$ & $V_{\text {u,brain,pred }}$ & $K_{\text {p,uu }}$ & $K_{\text {p,uu,cyto,pred }}$ & $K_{\text {p,uu,lyso,pred }}$ & $K_{\text {p,uu,cell,pred }}$ \\
\hline & & & & $m l / g$ \\
BIA 9-1079 & 0.0002 & $0.002(0.001)$ & $0.008(0.001)$ & 0.013 & 79.27 & 0.001 & 0.577 & 0.020 \\
Tolcapone & 0.0015 & $0.011(0.003)$ & $0.162(0.028)$ & 0.247 & 4.047 & 0.035 & 0.575 & 0.013 & 0.656 \\
\hline
\end{tabular}

$f_{\mathrm{u} \text {,plasma }}$, unbound drug fraction in plasma; $K_{\mathrm{p}}$, ratio of total brain-to-plasma $\mathrm{AUC}_{0-\mathrm{t}} ; K_{\mathrm{p} \text {,uu }}$, unbound brain-to-plasma ratio; $K_{\mathrm{p}, \mathrm{uu}, \text { cell,pred }}$, predicted unbound drug

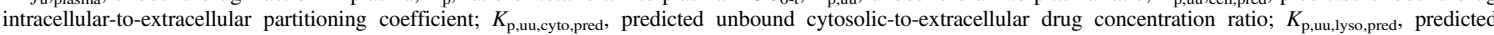
lysosomic-to-cytosolic unbound drug concentration ratio; $V_{\mathrm{u}}$,brain,pred, predicted volume of distribution of unbound drug in the brain. 
TABLE 5

Plasma and brain exposure of BIA 9-1079 and tolcapone after intravenous administration $(10 \mathrm{mg} / \mathrm{kg})$ to Wistar rats with or without coadministration of elacridar $(2.5 \mathrm{mg} / \mathrm{kg})$

The AUC is expressed in micrograms.hour/gram in brain tissue.

\begin{tabular}{|c|c|c|c|c|c|c|}
\hline \multirow{2}{*}{ Test Compound } & \multicolumn{2}{|c|}{$\mathrm{AUC}_{0-\mathrm{t}}$} & \multicolumn{2}{|c|}{$K_{\mathrm{p}}$} & \multicolumn{2}{|c|}{$K_{\mathrm{p}, \mathrm{uu}}$} \\
\hline & Vehicle & Elacridar & Vehicle & Elacridar & Vehicle & Elacridar \\
\hline & $\mu g . h / m l$ & $\mu g . h / m l$ & & & & \\
\hline BIA 9-1079 & & & & & & \\
\hline Plasma & 32.71 & 37.34 & 0.001 & 0.003 & 0.007 & 0.017 \\
\hline Brain & 0.037 & 0.095 & & & & \\
\hline Tolcapone & & & & & & \\
\hline Plasma & 27.31 & 28.59 & 0.002 & 0.004 & 0.041 & 0.095 \\
\hline Brain & 0.050 & 0.119 & & & & \\
\hline
\end{tabular}

$\mathrm{AUC}_{0-\mathrm{t}}$, area under the concentration-time curve from time zero to the last measurable concentration; $K_{\mathrm{p}}$, ratio of total brain-to-plasma $\mathrm{AUC}_{0-\mathrm{t}} ; K_{\mathrm{p}, \mathrm{uu}}$, unbound brain-to-plasma ratio.

all cell lines and in both directions, suggesting that BCRP was still able to compensate inward flux and identify nebicapone as an efflux substrate.

Additionally, the significant increase in brain exposure of BIA 9-1079 and tolcapone following the coadministration with elacridar confirms that P-gp and/or BCRP contribute to their limited access to the brain. Although other authors have reported low total or unbound brain-plasma ratios for tolcapone (Männistö and Kaakkola, 1999; Forsberg et al., 2003; Hakkarainen et al., 2010), this drug is a known peripheral and central COMT inhibitor, which could misleadingly convey that it crosses the BBB to a greater extent. In fact, $99 \%$ of brain COMT was inhibited after 0.5 hour of oral administration of tolcapone $(30 \mathrm{mg} / \mathrm{kg})$ to Wistar rats (Learmonth et al., 2002), probably due to its elevated potency, as evidenced by the very low $\mathrm{IC}_{50}$ values determined for membrane-bound $(2 \mathrm{nM})$ and cytosolic (3 nM) brain COMT (Vieira-Coelho and Soaresda-Silva, 1999). Hence, even though P-gp and BCRP severely hamper drug access to the CNS, efflux substrates can be centrally active if the administered dose is sufficient to result in pharmacologically active concentrations in the CNS. This also occurs with other COMT inhibitors such as nebicapone, which can cause peripheral and central COMT inhibition in vivo, despite having been herein identified as a BCRP substrate. Nebicapone displays a dose-dependent central COMT inhibitory effect since peripheral selectivity is observed at $3 \mathrm{mg} / \mathrm{kg}$ but lost at $30 \mathrm{mg} / \mathrm{kg}$ following oral administration in Wistar rats (Parada and Soares-da-Silva, 2003).

Comparatively, BIA 9-1079 crossed the BBB to an even lesser extent than tolcapone (35-fold lower $K_{\mathrm{p} \text {,uu }}$ ), meaning that peripheral effects are favored and CNS effects are much less probable. Indeed, the likelihood of CNS activity of a compound diminishes as $K_{\mathrm{p} \text {,uu }}$ decreases (HammarlundUdenaes, 2010). Furthermore, despite demonstrating peripheral selectivity and being a major metabolite of opicapone in animals, the contribution of BIA 9-1079 to the peripheral therapeutic effects of opicapone in humans is considered minor, given that BIA 9-1079 represents less than $20 \%$ of its systemic exposure (Rocha et al., 2013).

In conclusion, by using in vitro assays with MDCK II, MDCKMDR1, and MDCK-BCRP cells it was possible to successfully identify P-gp and BCRP inhibitors and substrates among COMT inhibitors. To the best of our knowledge, to date, there are no published in vitro studies characterizing the role of $\mathrm{P}$-gp and BCRP on the BBB transport of the tested COMT inhibitors. In vivo assays were performed for BIA 9-1079 and tolcapone, providing relevant information with regard to their extent of brain distribution and intrabrain tissue binding. Our studies are in line with the current notion that a conjugation of data from different parameters of CNS penetration is necessary to evaluate and explain brain-drug transport.

\section{Authorship Contributions}

Participated in research design: Bicker, Fortuna, Alves, Falcão.

Conducted experiments: Bicker, Fortuna.

Contributed new reagents or analytic tools: Soares-da-Silva.

Performed data analysis: Bicker, Fortuna, Alves, Soares-da-Silva, Falcão.

Wrote or contributed to the writing of the manuscript: Bicker, Fortuna, Alves, Soares-da-Silva, Falcão.

\section{References}

Abbott NJ, Dolman DEM, Yusof SR, and Reichel A (2014) In vitro models of CNS barriers, in Drug Delivery to the Brain: Physiological Concepts, Methodologies and Approaches (Hammarlund-Udenaes M, de Lange ECM, and Throne RG eds), pp 163-197, Springer-Verlag, New York.

Agarwal S, Hartz AMS, Elmquist WF, and Bauer B (2011) Breast cancer resistance protein and P-glycoprotein in brain cancer: two gatekeepers team up. Curr Pharm Des 17:2793-2802.

Almeida L, Rocha JF, Falcão A, Palma PN, Loureiro AI, Pinto R, Bonifácio MJ, Wright LC, Nunes T, and Soares-da-Silva P (2013) Pharmacokinetics, pharmacodynamics and tolerability of opicapone, a novel catechol- $O$-methyltransferase inhibitor, in healthy subjects: prediction of slow enzyme-inhibitor complex dissociation of a short-living and very long-acting inhibitor. Clin Pharmacokinet 52:139-151.

Annus Á and Vécsei L (2017) Spotlight on opicapone as an adjunct to levodopa in Parkinson's disease: design, development and potential place in therapy. Drug Des Devel Ther 11: 143-151.

Bauer M, Karch R, Zeitlinger M, Stanek J, Philippe C, Wadsak W, Mitterhauser M, Jäger W, Haslacher H, Müller M, et al. (2013) Interaction of 11C-tariquidar and 11C-elacridar with P-glycoprotein and breast cancer resistance protein at the human blood-brain barrier. J Nucl Med 54:1181-1187.

Bauer M, Römermann K, Karch R, Wulkersdorfer B, Stanek J, Philippe C, Maier-Salamon A, Haslacher H, Jungbauer C, Wadsak W, et al. (2016) Pilot PET study to assess the functional interplay between $\mathrm{ABCB} 1$ and $\mathrm{ABCG} 2$ at the human blood-brain barrier. Clin Pharmacol Ther 100:131-141.

Bicker J, Alves G, Fortuna A, and Falcão A (2014) Blood-brain barrier models and their relevance for a successful development of CNS drug delivery systems: a review. Eur J Pharm Biopharm 87:409-432.

Bonifácio MJ, Sutcliffe JS, Torrão L, Wright LC, and Soares-da-Silva P (2014) Brain and peripheral pharmacokinetics of levodopa in the cynomolgus monkey following administration of opicapone, a third generation nitrocatechol COMT inhibitor. Neuropharmacology 77:334-341. Brouwer KLR, Keppler D, Hoffmaster KA, Bow DAJ, Cheng Y, Lai Y, Palm JE, Stieger B, and Evers R; International Transporter Consortium (2013) In vitro methods to support transporter evaluation in drug discovery and development. Clin Pharmacol Ther 94:95-112.

Bungay P, Bagal S, and Pike A (2015) Designing peripheral drugs for minimal brain exposure, in Blood-Brain Barrier in Drug Discovery (Di L and Kerns EH eds) pp 446-462, John Wiley \& Sons, Inc., Hoboken, NJ.

Chen ZZ, Lu Y, Du SY, Shang KX, and Cai CB (2013) Influence of borneol and muscone on geniposide transport through MDCK and MDCK-MDR1 cells as blood-brain barrier in vitro model. Int J Pharm 456:73-79.

Cole S, Bagal S, El-Kattan A, Fenner K, Hay T, Kempshall S, Lunn G, Varma M, Stupple P, and Speed W (2012) Full efficacy with no CNS side-effects: unachievable panacea or reality? DMPK considerations in design of drugs with limited brain penetration. Xenobiotica 42:11-27.

Di L, Rong H, and Feng B (2013) Demystifying brain penetration in central nervous system drug discovery. Miniperspective. J Med Chem 56:2-12.

Dukes JD, Whitley P, and Chalmers AD (2011) The MDCK variety pack: choosing the right strain. BMC Cell Biol 12:43.

Ehlers A, These A, Hessel S, Preiss-Weigert A, and Lampen A (2014) Active elimination of the marine biotoxin okadaic acid by P-glycoprotein through an in vitro gastrointestinal barrier. Toxicol Lett 225:311-317.

European Medicines Agency (2012) Guideline on the investigation of drug interactions. European Medicines Agency, London.

Feng B, Mills JB, Davidson RE, Mireles RJ, Janiszewski JS, Troutman MD, and de Morais SM (2008) In vitro P-glycoprotein assays to predict the in vivo interactions of P-glycoprotein with drugs in the central nervous system. Drug Metab Dispos 36:268-275.

Food and Drug Administration (2012) Guidance for industry: drug interaction studies-study design, data analysis, implications for dosing, and labeling recommendations. Food and Drug Administration, Rockville, MD.

Forsberg M, Lehtonen M, Heikkinen M, Savolainen J, Järvinen T, and Männistö PT (2003) Pharmacokinetics and pharmacodynamics of entacapone and tolcapone after acute and repeated administration: a comparative study in the rat. J Pharmacol Exp Ther 304:498-506.

Fortuna A, Alves G, Soares-da-Silva P, and Falcão A (2013) Pharmacokinetics, brain distribution and plasma protein binding of carbamazepine and nine derivatives: new set of data for predictive in silico ADME models. Epilepsy Res 107:37-50.

Fridén M, Bergström F, Wan H, Rehngren M, Ahlin G, Hammarlund-Udenaes M, and Bredberg U (2011) Measurement of unbound drug exposure in brain: modeling of $\mathrm{pH}$ partitioning explains diverging results between the brain slice and brain homogenate methods. Drug Metab Dispos 39 353-362.

Funaki T, Onodera H, Ushiyama N, Tsukamoto Y, Tagami C, Fukazawa H, and Kuruma I (1994) The disposition of the tolcapone 3-O-methylated metabolite is affected by the route of administration in rats. J Pharm Pharmacol 46:571-574.

Gameiro M, Silva R, Rocha-Pereira C, Carmo H, Carvalho F, Bastos ML, and Remião F (2017) Cellular models and in vitro assays for the screening of modulators of P-gp, MRP1 and BCRP. Molecules 22:1-48.

Garberg P, Ball M, Borg N, Cecchelli R, Fenart L, Hurst RD, Lindmark T, Mabondzo A, Nilsson JE, Raub TJ, et al. (2005) In vitro models for the blood-brain barrier. Toxicol In Vitro 19: 299-334.

Giacomini KM, Huang SM, Tweedie DJ, Benet LZ, Brouwer KL, Chu X, Dahlin A, Evers R, Fischer V, Hillgren KM, et al.; International Transporter Consortium (2010) Membrane transporters in drug development. Nat Rev Drug Discov 9:215-236. 
Gonçalves D, Alves G, Fortuna A, Soares-da-Silva P, and Falcão A (2013) An HPLC-DAD method for the simultaneous quantification of opicapone (BIA 9-1067) and its active metabolite in human plasma. Analyst (Lond) 138:2463-2469.

Gonçalves D, Alves G, Fortuna A, Soares-da-Silva P, and Falcão A (2016) Development of a liquid chromatography assay for the determination of opicapone and BIA 9-1079 in rat matrices. Biomed Chromatogr 30:312-322.

Gonçalves D, Alves G, Soares-da-Silva P, and Falcão A (2012) Bioanalytical chromatographic methods for the determination of catechol- $O$-methyltransferase inhibitors in rodents and human samples: a review. Anal Chim Acta 710:17-32.

Hakkarainen JJ, Jalkanen AJ, Kääriäinen TM, Keski-Rahkonen P, Venäläinen T, Hokkanen J, Mönkkönen J, Suhonen M, and Forsberg MM (2010) Comparison of in vitro cell models in predicting in vivo brain entry of drugs. Int J Pharm 402:27-36.

Hammarlund-Udenaes M (2010) Active-site concentrations of chemicals-are they a better predictor of effect than plasma/organ/tissue concentrations? Basic Clin Pharmacol Toxicol 106:215-220.

Hammarlund-Udenaes M (2014) Pharmacokinetic concepts in brain drug delivery, in Drug Delivery to the Brain: Physiological Concepts, Methodologies and Approaches (Hammarlund Udenaes M, de Lange ECM, and Throne RG eds), pp 127-161, Springer-Verlag, New York.

Hellinger E, Veszelka S, Tóth AE, Walter F, Kittel A, Bakk ML, Tihanyi K, Háda V, Nakagawa S Duy TD, et al. (2012) Comparison of brain capillary endothelial cell-based and epithelial (MDCK-MDR1, Caco-2, and VB-Caco-2) cell-based surrogate blood-brain barrier penetration models. Eur J Pharm Biopharm 82:340-351.

Hu HH, Bian YC, Liu Y, Sheng R, Jiang HD, Yu LS, Hu YZ, and Zeng S (2014) Evaluation of blood-brain barrier and blood-cerebrospinal fluid barrier permeability of 2-phenoxy-indan-1-one derivatives using in vitro cell models. Int J Pharm 460:101-107.

Hubatsch I, Ragnarsson EGE, and Artursson P (2007) Determination of drug permeability and prediction of drug absorption in Caco-2 monolayers. Nat Protoc 2:2111-2119.

Kalvass JC, Polli JW, Bourdet DL, Feng B, Huang SM, Liu X, Smith QR, Zhang LK, and ZamekGliszczynski MJ; International Transporter Consortium (2013) Why clinical modulation of ef flux transport at the human blood-brain barrier is unlikely: the ITC evidence-based position. Clin Pharmacol Ther 94:80-94.

Kamiie J, Ohtsuki S, Iwase R, Ohmine K, Katsukura Y, Yanai K, Sekine Y, Uchida Y, Ito S, and Terasaki T (2008) Quantitative atlas of membrane transporter proteins: development and application of a highly sensitive simultaneous LC/MS/MS method combined with novel in-silico peptide selection criteria. Pharm Res 25:1469-1483

Kiss LE, Ferreira HS, and Learmonth DA (2008) Efficient synthesis of 2-(trifluoromethyl)nicotinic acid derivatives from simple fluorinated precursors. Org Lett 10:1835-1837.

Kiss LE and Soares-da-Silva P (2014) Medicinal chemistry of catechol $O$-methyltransferase (COMT) inhibitors and their therapeutic utility. J Med Chem 57:8692-8717.

Learmonth DA, Vieira-Coelho MA, Benes J, Alves PC, Borges N, Freitas AP, and da-Silva PS (2002) Synthesis of 1-(3,4-dihydroxy-5-nitrophenyl)-2-phenyl-ethanone and derivatives as potent and long-acting peripheral inhibitors of catechol-O-methyltransferase. J Med Chem 45:685-695.

Li L, Yao QQ, Xu SY, Hu HH, Shen Q, Tian Y, Pan LY, Zhou H, Jiang HD, Lu C, et al. (2014) Cyclosporin A affects the bioavailability of ginkgolic acids via inhibition of P-gp and BCRP. Eur J Pharm Biopharm 88:759-767.

Loryan I, Sinha V, Mackie C, Van Peer A, Drinkenburg W, Vermeulen A, Morrison D, Monshouwer M, Heald D, and Hammarlund-Udenaes M (2014) Mechanistic understanding of brain drug disposition to optimize the selection of potential neurotherapeutics in drug discovery. Pharm Res 31:2203-2219.

Löscher W and Potschka H (2005) Role of drug efflux transporters in the brain for drug disposition and treatment of brain diseases. Prog Neurobiol 76:22-76.

Mahar Doan KM, Humphreys JE, Webster LO, Wring SA, Shampine LJ, Serabjit-Singh CJ, Adkison KK, and Polli JW (2002) Passive permeability and P-glycoprotein-mediated efflux differentiate central nervous system (CNS) and non-CNS marketed drugs. J Pharmacol Exp Ther 303:1029-1037.

Männistö PT and Kaakkola S (1999) Catechol-O-methyltransferase (COMT): biochemistry, molecular biology, pharmacology, and clinical efficacy of the new selective COMT inhibitors. Pharmacol Rev 51:593-628.

Montesinos RN, Moulari B, Gromand J, Beduneau A, Lamprecht A, and Pellequer Y (2014) Coadministration of P-glycoprotein modulators on loperamide pharmacokinetics and brain distribution. Drug Metab Dispos 42:700-706.
Napolitano A, Bellini G, Borroni E, Zürcher G, and Bonuccelli U (2003) Effects of peripheral and central catechol- $O$-methyltransferase inhibition on striatal extracellular levels of dopamine: a microdialysis study in freely moving rats. Parkinsonism Relat Disord 9 $145-150$.

Parada A and Soares-da-Silva P (2003) BIA 3-202, a novel catechol- $O$-methyltransferase inhibitor, reduces the peripheral $O$-methylation of L-DOPA and enhances its availability to the brain. Pharmacology 68:29-37.

Pavek P, Merino G, Wagenaar E, Bolscher E, Novotna M, Jonker JW, and Schinkel AH (2005) Human breast cancer resistance protein: interactions with steroid drugs, hormones, the dietary carcinogen 2-amino-1-methyl-6-phenylimidazo(4,5-b)pyridine, and transport of cimetidine. $J$ Pharmacol Exp Ther 312:144-152.

Polli JW, Wring SA, Humphreys JE, Huang L, Morgan JB, Webster LO, and Serabjit-Singh CS (2001) Rational use of in vitro P-glycoprotein assays in drug discovery. J Pharmacol Exp Ther 299:620-628.

Reichel A (2014) Integrated approach to optimizing CNS penetration in drug discovery: from the old to the new paradigm and assessment of drug-transporter interactions, in Drug Delivery to the Brain: Physiological Concepts, Methodologies and Approaches (Hammarlund-Udenaes M, de Lange ECM, and Throne RG eds) pp 339-374, Springer-Verlag, New York.

Rocha JF, Almeida L, Falcão A, Palma PN, Loureiro AI, Pinto R, Bonifácio MJ, Wright LC, Nunes $\mathrm{T}$, and Soares-da-Silva P (2013) Opicapone: a short lived and very long acting novel catechol- $O$ methyltransferase inhibitor following multiple dose administration in healthy subjects. Br J Clin Pharmacol 76:763-775.

Römermann K, Helmer R, and Löscher W (2015) The antiepileptic drug lamotrigine is a substrate of mouse and human breast cancer resistance protein (ABCG2). Neuropharmacology 93:7-14. Shawahna R, Uchida Y, Declèves X, Ohtsuki S, Yousif S, Dauchy S, Jacob A, Chassoux F, Daumas-Duport C, Couraud PO, et al. (2011) Transcriptomic and quantitative proteomic analysis of transporters and drug metabolizing enzymes in freshly isolated human brain microvessels. Mol Pharm 8:1332-1341.

Silva T, Mohamed T, Shakeri A, Rao PPN, Martínez-González L, Pérez DI, Martínez A, Valente MJ, Garrido J, Uriarte E, et al. (2016) Development of blood-brain barrier permeable nitrocatechol-based catechol $O$-methyltransferase inhibitors with reduced potential for hepatotoxicity. J Med Chem 59:7584-7597.

Tournier N, Goutal S, Auvity S, Traxl A, Mairinger S, Wanek T, Helal OB, Buvat I, Soussan M, Caillé F, et al. (2017) Strategies to inhibit ABCB1- and ABCG2-mediated efflux transport of erlotinib at the blood-brain barrier: a PET study in non-human primates. J Nucl Med 58:117-122

Uchida Y, Ohtsuki S, Katsukura Y, Ikeda C, Suzuki T, Kamiie J, and Terasaki T (2011) Quantitative targeted absolute proteomics of human blood-brain barrier transporters and receptors. I Neurochem 117:333-345.

Urquhart BL, Ware JA, Tirona RG, Ho RH, Leake BF, Schwarz UI, Zaher H, Palandra J, Gregor JC, Dresser GK, et al. (2008) Breast cancer resistance protein (ABCG2) and drug disposition: intestinal expression, polymorphisms and sulfasalazine as an in vivo probe. Pharmacogene Genomics 18:439-448.

Vieira-Coelho MA and Soares-da-Silva P (1999) Effects of tolcapone upon soluble and membranebound brain and liver catechol- $O$-methyltransferase. Brain Res 821:69-78.

Wang C and Williams NS (2013) A mass balance approach for calculation of recovery and binding enables the use of ultrafiltration as a rapid method for measurement of plasma protein binding for even highly lipophilic compounds. J Pharm Biomed Anal 75:112-117.

Wang Q, Rager JD, Weinstein K, Kardos PS, Dobson GL, Li J, and Hidalgo IJ (2005) Evaluation of the MDR-MDCK cell line as a permeability screen for the blood-brain barrier. Int J Pharm 288:349-359.

Weidner LD, Zoghbi SS, Lu S, Shukla S, Ambudkar SV, Pike VW, Mulder J, Gottesman MM, Innis RB, and Hall MD (2015) The inhibitor Ko143 is not specific for ABCG2.J Pharmacol Exp Ther 354:384-393.

Address correspondence to: Dr. Gilberto Alves, Faculty of Health Sciences, CICS-UBI-Health Sciences Research Centre, University of Beira Interior, Avenue Infante D. Henrique, 6200-506 Covilhã, Portugal. E-mail: gilberto@fcsaude.ubi.pt 